\title{
Language Motivation, Metacognitive Strategies and Language Performance: A Cause and Effect Correlation
}

\author{
Ag. Bambang Setiyadi (Corresponding author) \\ Lampung University, Sumantri Brojonegoro, 1 Bandarlampung, Indonesia \\ E-mail: bambang_setiyadi76@yahoo.co.id \\ Mahpul \\ Lampung University, Sumantri Brojonegoro, 1 Bandarlampung, Indonesia \\ E-mail: mahpul_mahpul@yahoo.com \\ Muhammad Sukirlan \\ Lampung University, Sumantri Brojonegoro, 1 Bandarlampung, Indonesia \\ E-mail: muhammad_sukrilan@yahoo.co.id
}

Bujang Rahman

Lampung University, Sumantri Brojonegoro, 1 Bandarlampung, Indonesia

E-mail: bujang.suropati@gmail.com

Received: 13-08-2016

Published: 10-12-2016
Accepted: 10-10-2016

doi:10.7575/aiac.ijalel.v.5n.7p.40
Advance Access Published: November 2016

URL: http://dx.doi.org/10.7575/aiac.ijalel.v.5n.7p.40

The research is financed by Lampung University, Indonesia with with Project No. 156/UN26/8/LPPM/2015.

\begin{abstract}
Studies on motivation in language learning have been well documented. The role of motivation in determining the use of learning strategies has been identified and the correlation between motivation and language performance has been determined. However, how language motivation in EFL context is classified and how language motivation is intercorrelated with the use of metacognitive and language performance has still not become widespread in the literature on language learning. The current study identified how language motivation in the context of EFL setting was classified and, then, how language motivation affected the use of metacognitive strategies and language performance. It was found that in the EFL setting three motivational orientations existed; the three motivational orientations were extrinsic motivation, international orientation and intrinsic motivation. The findings revealed that the EFL learners in the current study had more international orientation in learning English and were more extrinsically motivated than intrinsically motivated. The empirical evidence suggests that language motivation predicted learning success through the mediation of the use of metacognitive strategies. Suggestions for further research are also discussed.
\end{abstract}

Keywords: international orientation, language motivation, language performance, metacognitive strategies

\section{Introduction}

The role of motivation in language learning in general has been well documented but studies on the role of motivation in strategy use are very rare (see Kafipour, Noordin \& Pezeshkian, 2011; Maclntyre and Noels, 1996). More recently, Chang and Liu (2013) conducted a study investigated the correlation between motivation and the language learning strategies and found out that there were differences among EFL Taiwan students with different levels of learning motivation in terms of their strategy use. In their study metacognitive strategies were found to have the highest correlation with motivation; the most often used strategies the students by the highly motivated students were metacognitive strategies (p. 204). However, the correlation between motivation and language learning strategies in their study is not in line with the findings in a study by Khamkhien (2010). His study, which involved two groups of students in Thailand and Vietnam, indicates that overall the highly-motivated and lowly-motivated students are not different in the use of learning strategy categories even though the study shows that the highly-motivated students reported higher use of metacognitive category than the lowly-motivated students (p.77).

In Chang and Liu's (2013) study the questionnaire used to measure student learning motivation in learning English as a foreign language was adapted from Gardner's study, which has been developed based on a second language learning (Gardner, Masgoret, Tennant, Mihic, 2004). In Khamkhien's (2010) study, the questionnaire of the motivation for a similar context was developed to group students under those with higher motivation and those with lower motivation. 
The two studies have provided empirical evidence that the correlation between motivation and the choice of learning strategies, especially metacognitive strategies, do exist in EFL setting. However, the studies did not group the language learners based on their motivational types, which seem to be the main point of classifying language learners based on their reasons of learning another language.

Many studies have provided evidence that motivated students immersed themselves in using metacognitive strategies in language learning. Metacognitive strategies have also been proved to affect success in foreign language learning (Zhang \& Seepho, 2013; Magogwe \& Oliver, 2007). It has been revealed that language motivation, metacognitive strategies and language performance are inter-correlated but how they are inter-correlated has not been well explored. This study addresses how language motivation was classified and how language motivation, metacognitive strategies and language performance were correlated.

\subsection{Literature Review}

The dichotomy of language learners based on their reasons, referring to the self determination theory (Noels, Pelletier \& Vallerand, 2000; Vallerand, Pelletie \& Koestner, 2008), seems important to determine the reasons of learning another language. A well known dichotomy of motivation in general education as intrinsic motivation and extrinsic motivation is widely accepted in language learning. Extrinsic motivation refers to behaviours an individual performs to receive some extrinsic reward, e.g., learning English in order to get a better job while intrinsic motivation refers to behaviours whose rewards are internal, e.g., the joy of learning English.

Another dichotomy which is also commonly used to determine reasons of learning a language is that between instrumental and integrative motivation, which can be traced back to a study by Gardner and Lambert in 1959 (see also Gardner, 2000; Kissau, Kolano \& Wang, 2010). They define that instrumental motivation as the reasons of learning a foreign language that reflect more utilitarian value of linguistic achievement. This type of motivation is equal to extrinsic motivation, which is related to rewards are external to language learning. Different from instrumental motivation, of which rewards are external to the activity, integrative motivation refers to internal reason to language learning. This type of motivation refers to individual's willingness and interest in having social interaction with members of the L2 group (Gardner and Lambert, 1959). Gardner and Lambert state that with integrative motivation language learners learn another language because they want to learn more about the language group.

As mentioned earlier that some studies have shown the correlation between motivation and metacognitive strategies. Metacognitive strategies in language learning have been introduced in the studies by O'Malley, Chamot, StewnerManzanares, Kuper, and Russo (1985) and Oxford (1990). The concept of metacognition in their studies refers to similar processes in acquiring another language. Oxford (1990) states that metacognitive strategies include: centering, learning, arranging and planning learning, and evaluating learning. Actually, some previous studies have already introduced metacognitive processes but they do not name them as such. For example, Rubin (1981) mentions monitoring strategy under the name direct learning. Naiman, Frochlich, Stern and Todesco (1978) identify similar strategies, but they regard the strategies as a single category. Politzer and Groarty (1985) classify metacognitive strategeis under three categories: classroom behavior, learning behavior during individual study and interacting with others outside the classroom. Unlike O’Malley, Chamot, Stewner- Manzanares, Kuper, and Russo (1985) and Oxford (1990), Wenden (1991) also identifies metacognitive strategies but the strategies are grouped under the name selfmanagement strategies. Many studies have investigated metacognitive strategies in language learning and different names and categories have been used to refer to the same concept. Different from other studies, which classified metacognitive strategies under a single category for the four language skills, Setiyadi (2014) classifies metacognitive strategies for different language skills in separated categories: metacognitive strategies of speaking, metacognitive strategies of listening, metacognitive strategies of reading and metacognitive strategies of writing. Since in EFL setting language learners tend to learn the language based on language skills separately, a classification of learning strategies based on language skills may be appropriate to be used in this study.

In order to get a better concept of metacognition in language learning, the concept of cognition is useful to understand as a comparison. Sherrod (1982, p. 9) indicates that cognitive strategies refer to how people attend to information in the environment and how the people process that information in their brains. In general education, Stratton and Hays $(1989$, p.111) states that the study of metacognition includes the study of the ways in which people monitor and control their own cognitive activity. Sheinker and Sheinker (1989, p.vi) emphasize that students studying metacognitively may use strategies for self-direction, self-monitoring, self- evaluation, and self-correction. Different from cognition, which involves mental processing, metacognition in language learning involves processes related to monitoring and evaluating what has been done and planning what to do in acquiring another language. In the context of language learning metacognitive strategies are a group of strategies which language learners employ independently; they rely more on themselves to direct, monitor and evaluate their learning, and correct their errors while learning the language skills. By using metacognitive strategies, language learners try to regulate their own learning.

It is understood that language learners who employ metacognitive strategies more often are expected to be more autonomous and to be more self-regulated learners since the use of metacognitive strategies is linked to their beliefs about their ability to do the task, which is one of three components of self regulated learning (Pintrich \& De Groot, 1990, p. 33). The other two components of self regulated learning are goals the students have to do the task and their emotional reactions to the task they have to do (pp. 33 -340). It may be concluded that the use of metacognitive strategies is a part of self regulation introduced by Pintrich (1999). The use of metacognitive strategies may trigger language learners to be self-directed. This is indicated in a study by $\mathrm{Su}$ and Duo (2010) that the more strategies 
language learners are able to apply to their learning, the more self-directed they will become; though, they do not refer to the use of metacognitive strategies specifically.

As suggested by Schunk ((2005, p.91), research is needed on contextual influences on self-regulation and especially in different content areas and across contexts since different relations may exist among goal orientations and selfregulation outcomes as a function of cultural background. How self-regulated learning may be moderated by the contexts of English learned as ESL or EFL and how self-regulation and ethnicity may be correlated seems to worthy exploring. In sum, identifying the correlation between self-regulated learning of EFL students and their motivational types in a certain cultural background will provide English teachers a better understanding of teaching EFL accordingly. Therefore, this study was meant to identify motivational orientations of language learners in EFL setting, and examine the relationship between their motivational orientations, their use of metacogntive strategies and language performance. Firstly, an attempt was made to classify the tertiary EFL students based on their reasons in learning the target language. An effort was then made to identify students' use of metacognitive learning strategies and correlated with their motivational orientations and their performance. Therefore, the present study attempted to address the following research questions:

1. How was language motivation in the context of EFL classified?

2. How was language motivation, metacognitive strategies and language performance correlated?

\section{Methodology}

This study was an ex post facto research conducted at the Language Centre of a university in Indonesia. To answer the first research question, descriptive analysis was undertaken to identify whether the motivational orientations developed in the questionnaire existed and to determine the reliability of the questionnaire by running reliability analyses. To answer the second research question, correlation analyses were run to identify how motivational orientations, learning strategies and language performance were correlated. The analysis was then continued by undertaking regression analyses to ascertain how language motivation predicts the use of metacognitive strategies and how the two variables predict language performance.

\subsection{Participants}

Five hundred and eighty one first year undergraduates from Exact and Social Science Departments (male=272; female=309) form the sample for this study, with an age range from 18 to 22 years old $(M=20.24, S D=.96)$. Approximately 1 week prior to the start of the first semester, at the university new students were invited to have English Entrance Test. Before the students worked on the English test, the students were briefed on the nature of the questionnaires and confidentiality was confirmed. They were allowed as much time as they needed to complete the questionnaires. The reasons of choosing the participants was that the students had enough English proficiency since they had studied English long enough and experienced in using learning strategies since Junior High School.

\subsection{Instrument}

The research instrument for motivation was a self-report questionnaire written in Indonesian. The questionnaire was adapted from Gardner, Tremblay, \& Masgoret (1997) and Abrar-Ul-Hasaan (2014). Item nos. 1 to 4 were adapted from Gardner's measurement to identify the existence of integrative orientation in learning English as a foreign language in Indonesian context while item nos. 5 to 12 were developed from Abrar-Ul-Hasaan to classify learners' motivation under extrinsic and intrinsic orientation. The questionnaire measures motivational orientations by providing choices ranging from "never true of me "to "always true of me" and the scores range from 1 to 4.

To identify metacognitive strategies employed in learning the skills of English as a foreign language, Language Learning Strategy Questionnaire (LLSQ) developed by "Author" (2014), which has been developed by considering the use of learning strategies in the four language skills in the context of EFL setting, were used. Some metacognitive learning strategies developed in the LLSQ were developed from didfferent sources (O'Malley, Chamot, StewnerManzanares, Kuper, \& Russo, 1985; Oxford, 1990; Politzer \& Groarty, 1985; Rubin, 1975) and some others were newly developed. The language strategies under metacognitive strategeis consists of 21 items, namely, 5 items of learning strategies in speaking, 6 items of learning strategies in listening, 6 items of learning strategies in reading and items of 4 learning strategies in writing. The LLSQ measures learning strategies employed by English learners by providing choices ranging from "never " to "always" and the scores range from 1 to 4 . The two questionnaires were translated into Indonesian before they were administered.

\section{3 Data Analysis}

The collected data were recorded in SPSS. To identify the motivational orientations of the EFL students in the current study, the data were analyzed by running descriptive analyses. Reliability analyses were also undertaken to determine the reliability of the language motivation and each motivational orientation, and metacognitive strategies. To identify the interaction between the language motivation and its orientations, metacognitive strategies and language performance, correlation analyses were run and, then, regression analyses were undertaken to identify how language motivation, learning strategies and language performance could be predicted from one another. 


\section{Results}

\section{1 Descriptive measures and reliability of the motivation}

To measure the internal consistency of the hypothesized scales explored in this study, Cronbach Alpha coefficients of internal consistency were computed for each: the motivation scale, the scales of motivational orientations and the scale of metacognitive strategies. Table 1 provides evidence that the motivation scale, the three subscales of motivational orientations and the use of metacognitive strategies have acceptable alpha values. A relatively lower alpha value was found for intrinsic motivation. However, intrinsic motivation was maintained for analysis due to its importance in this study and the lower alpha value of the intrinsic motivation should be kept with caution when interpreting the findings of this study. All the scales in this study were internally consistent; therefore, the criteria on internal consistency of the constructs were met in this analysis.

The mean values and standard deviations of motivation, the three subscales of motivational orientations, and the metacognitive strategies the students reported using are also presented in Table 1. The scores ranged from 1 to 4 . The finding as provided in Table 1 shows that the mean value of motivation was 3. 19. The empirical data also shows that extrinsic motivation had the highest mean value $(M=3.6)$ followed by the mean value of integrative orientation $(\mathrm{M}=$ 3.1). The mean value of the intrinsic motivation $(M=2.73)$ was the lowest among the three subscales of motivational orientations. In general, the students in this study had high motivation in learning English. The mean values of the motivational orientations suggest that the students in this study were more interested in learning English because of rewards external to the process of learning (extrinsic motivation and international orientation). Their reason of learning English which is internal in their learning process (intrinsic motivation) was not as high as their reasons for external rewards. For their metacognitive strategies, the mean value was not very high $(\mathrm{M}=2.70)$, suggesting that the students did not learn English autonomously $(\mathrm{M}<3.0)$.

Table 1. Descriptive measures reliability of the variables

\begin{tabular}{llcl}
\hline & Mean & Standard Deviation & Cronbach alpha \\
\hline Language motivation & 3.19 & .35 & .78 \\
a. Extrinsic motivation & 3.61 & .38 & .70 \\
b. International orientation & 3.11 & .50 & .78 \\
c. Intrinsic motivation & 2.73 & .48 & .35 \\
Metacognitive strategies & 2.70 & .46 & .92 \\
\hline
\end{tabular}

\subsection{Correlations among the variables}

To determine how motivational orientations correlate with the use of metacognitive strategies, the three subscales of motivational orientation were correlated with the scale of metacognitive strategies. As can be seen from Table 2 the three subscales of motivational orientation: extrinsic motivation, international orientation and intrinsic motivation were statistically significantly correlated with metacognitive strategies. While both extrinsic motivation and intrinsic motivation show an equally positive correlation, it is international orientation that has the strongest linear correlation with metacognitive strategies, suggesting that the students' international orientation had the highest positive effects on their metacognitive strategies among the three motivational orientations.

The analysis also indicates the three subscales scales were positively and correlated significantly one another. To the degree that the subscales of motivational orientations correlate, they shared variance, and the magnitude of $\mathrm{r}^{2}$ indicates the amount of variance that is interrelated (Hatch \& Lazaraton, 1991, pp.440-441). It may imply that the students in this study did not have a single sub-scale of motivational orientations only. The inter-correlation among the sub-scales may be understood that the learners had a combination of the motivational orientations in learning English.

Students' motivation, which is a combination of the three motivational orientations, was also significantly correlated with language performance. However, the linear relationship of motivation and language performance was not particularly strong. Compared with all the subscales of motivational orientations and the language motivation, the use of metacognitive strategies had the strongest correlation with language performance. This suggests that the use of metacognitive strategies by the students in this study had more positive effects on language performance than each motivational orientation or the language motivation.

Table 2. Correlations of the variables

\begin{tabular}{|c|c|c|c|c|c|c|}
\hline & (a) & (a1) & (a2) & (a3) & (b) & (c) \\
\hline Language motivation (a) & - & & & & & \\
\hline Extrinsic motivation (a1) & $.69^{* *}$ & - & & & & \\
\hline International orientation (a2) & $.86^{* *}$ & $.38^{* *}$ & - & & & \\
\hline Intrinsic motivation (a3) & $.67^{* *}$ & $.30^{* *}$ & $.39^{* *}$ & - & & \\
\hline Metacognitive strategies (b) & $.36^{* *}$ & $.27^{* *}$ & $.30^{* *}$ & $.27^{* *}$ & - & \\
\hline Language performance (c) & $.31^{* *}$ & $.24^{* *}$ & $.27^{* *}$ & $.20^{* *}$ & $.78^{* *}$ & - \\
\hline
\end{tabular}

${ }^{* *} \mathrm{p}<.01$ 
Regression analysis was also undertaken to ascertain whether motivational orientations predicted the use of metacognitive strategies and to identify which motivational orientation best predicted the use of metacognitive strategies. Regression analysis was also carried out to determine to what extent the contribution of students' motivation, which consists of three orientations, predicted language performance. For motivational orientations, the use of metacognitive strategies was taken as a dependant variable. However, the use of metacognitive strategies, together with language motivation, acted as an independent variable for language performance.

Table 3 provides data on the multiple regressions undertaken to see how the subscales of motivational orientation contribute to the variance of metacognitive strategies. The analysis shows that the three subscales shared statistically significant predictive variance of metacognitive strategies. Among the three motivational orientations, international orientation contributed the most explained variance $(\beta=.19, \mathrm{p}<.01)$, followed by the other two orientations: the extrinsic motivation $((\beta=.15, \mathrm{p}<.01)$ and intrinsic motivation $((\beta=.15, \mathrm{p}<.01)$. The last two motivations explained an equal percentage of the variance. In total, the motivational orientations together contributed $14 \%$ of the variance associated with the use of metacognitive strategies. It can be argued that the motivational orientations contributed potentially available variance of metacognitive strategies. International orientation, extrinsic motivation and intrinsic motivation contributed $9 \%, 7 \%$ and $7 \%$ of the variance respectively.

As discussed earlier, motivation and metacognitive strategies were significantly correlated with language performance $(\mathrm{r}=31, \mathrm{p}<.01$ and $\mathrm{r}=78, \mathrm{p}<.01)$. To find out which of the two independent variables acted as predictors of language performance, multiple regression analysis with the stepwise approach was carried out. As indicated in Table 3, when the two independent variables were included in the equation, only the use of metacognitive strategies was statistically significant in predicting the score of language performance. The analysis shows that metacognitive strategies best predicted the contribution of language performance $(\beta=.77, p<.01)$. It was found out that altogether both language motivation and metacognitive strategies accounted $61 \%$ of the variance of language performance. Specifically, the variable of metacognitive strategies contributed $61 \%$ of the variance of language performance and motivation did not significantly predict the variance. The use of metacognitive strategies acted as a very strong predictor of language performance. Language motivation may be understood primarily to be directly related to the use of metacognitive strategies and not as a factor that had a direct effect on language performance. The students' motivation predicted the use of their metacognitive strategies and, in turn, their metacognitive strategies predicted their language performance.

Table 3. Regression Analysis of motivational orientations with metacognitive strategies

\begin{tabular}{llll}
\hline Variables & $B$ & SE B & Beta $(\beta)$ \\
\hline International orientation & .18 & .04 & $.19^{* *}$ \\
Extrinsic motivation & .19 & .05 & $.15^{* *}$ \\
Intrinsic motivation & .16 & .04 & $.15^{* *}$ \\
$\mathrm{R}^{2}$ & $14 * *$ & & \\
\hline$* * \mathrm{p}<.01$ & & &
\end{tabular}

Table 4. Regression Analysis of motivation and metacognitive strategies with language performance

\begin{tabular}{llll}
\hline Variables & $B$ & SE B & Beta $(\beta)$ \\
\hline Metacognitive strategies & 41.14 & 1.48 & $.77^{* *}$ \\
Motivation & 2.50 & 2.07 & .03 \\
$\mathrm{R}^{2}$ & $.61^{* *}$ & & \\
\hline$* * \mathrm{p}<.01$ & & &
\end{tabular}

\section{Discussion}

The main goal of this study was to provide some information regarding the influence of language motivation on metacognitive strategies, and the influence of language motivation and metacognitive strategies on language performance. Language motivation in this study focus on students' reasons of learning English, which has been categorized under extrinsic orientation, international orientation and intrinsic orientation. Students' self regulated learning in language learning was more specifically operationalized in the use of metacognitive strategies, which cover the four language skills: listening, speaking, reading and writing. The multiple regression analysis shows that motivational orientations may predict the use of metacognitive strategies. The analyses also suggest the extent of the contribution of the variables of language motivation and metacognitive strategies to students' language performance.

\subsection{Motivational orientations in EFL setting}

The empirical data in this sudy suggests that a relatively new category of motivational orientation: international orientation do exist in the context of EFL learning. This category might not have been an issue in the past. In many 
studies a similar classification has been used by referring to integrative motivation, which was inspired by Gardner's studies (Gardner and Lambert, 1959; 1972). When Gardner's dichotomy of language motivation was introduced in 1960s in Canada, integration was an important issue. Integrative motivation, which refers to having interest in social interaction with members of the L2 group, was believed to be an important orientation in language learning (Gardner, Tremblay, \& Masgoret, 1997; Gardner, 2000). However, the empirical data in this study shows that the EFL learners have both extrinsic motivation and international orientation, which is equal with integrative motivation in Gardner's theory, with equally high intensity. It may be understood that measuring integrative motivation in the context of EFL learning is not relevant because the students may not be motivated to integrate with native speakers of the target language since integration with another group is not an important issue for EFL learners. They may be interested in having social interaction with people from other countries, not specifically native speakers of English, by using English. A study by Warden and Lin (2000), which was conducted with students in Taiwan, indicates that integrative motivation in the context of EFL is notably absent and they suggest that that EFL instruction in Taiwan is highly informed by imported ESL theory.

The findings also revealed that the EFL learners in the current study had more international orientation in learning English and were more extrinsically motivated than intrinsically motivated. They learned English as a foreign language in order to arrive at some instrumental end, and not because of inherent interest in learning English. They had reasons which are external to learning English as a foreign language. This trend is supported by a study by Ngo, Spooner-Lane and Mergler (2015), which involved EFL learners in Vietnam. This may be argued that EFL learners tend to be more extrinsically motivated than intrinsically motivated in learning English (see also Thang, Ting \& Mohd Jaafar, 2011)

Motivational orientations in learning a foreign language may change. Kormos and Scizer (2014) state that in the era of globalization English has become a lingua franca. They also argue that in the era of globalization the reason of learning the target language has become separated from its native speakers and their cultures. Many studies may include interest in foreign or international affairs, willingness to go overseas to study or work, readiness to interact people from different cultures (Kormos and Scizer, 2014, p. 277). International orientation in language motivation, which has been proved to exist in this study, may be a substitute to integrative motivation, which is often interpreted as interest in the native speakers of English only. International orientation seems to have been a part of language learning motivation in the era of globalization (Lamb, 2004; Lamb \& Wedell, 2014).

Referring to the empirical data, the students were not grouped under a single type of motivational orientations. The significant positive correlations among the types of motivation may imply that the reasons for learning English as a foreign language in this study were not mutually exclusive. The students did not have only a single type of motivation in learning English as a foreign language. The EFL learners in the current study learned English with different reasons with relatively equal intensity. This is in line with a finding conducted by Pintrich (1999) in general education that students can pursue multiple goals simultanously.

\subsection{The inter-correlation among motivational orientations, metacognitive strategies and performance}

It is likely that in this study the more motivated students immersed themselves more in the language learning tasks, which triggered them to use metacognitive strategies. Metacognitive strategies, then, affected the success in foreign language learning. This finding may contribute to the issue whether motivation in learning a foreign language predicts learning success or learning success predicts motivation (Gardner, 1988, pp.111-2; and Gass \& Selinker, 1994, pp.2557). Gass and Selinker state that which of the two predicts the other is a major dispute about motivations and second language learning. The relationship between motivation and metacognitive strategies found in this study may suggest a notion that their reasons of learning English, which are then operationalized in the use of metacognitive strategies, predicted learning success. Therefore, it may be understood that motivation predicted learning success through the mediation of metacognitive strategies. Motivational orientation, which is a part of motivational factors, can be a precussor to the use of effective- regulatory strategies (Kormos and Scizer, 2014, p. 281). A study on the correlation among the three variables: motivation, the use of learning strategies and language performance was also conducted by Watson, Mcsorley, Foxcroft and Watson (2004). Even though their study indicate that there was intercorrelation among the three variables but their study did not show a causal relationship among the variables and no indication of how the variables would affect one another.

It may be argued whether motivated students of EFL are autonomous language learners or not. Kormos and Scizer (2014) conclude that motivational factors exert their effect on autonomous learning behaviour through the mediation of self regulation strategies (291). In a study which involved college students within a Western culture, Pintrich (1999) indicates that one of the findings was that motivational orientations predicted the use of self regulated learning. In his study students with different orientations: orientation of mastery, extrinsic orientation and orientation of relative ability would employ different self regulatory strategies ( p. 466). Pintrich (1999) also suggest to test the generalizability of the findings within other cultures where the self is not the central. The empirical evidence in the current study, which was conducted in EFL context in an Indonesian setting, supported the notion that language motivation predicted the use of metacognitive strategies. Even though extrinsic motivation and self regulation was negatively correlated for college students in Pintrich's (1999) study, it seems that the cause-effect relationship between goal setting and the use of selfregulated learning hold for different groups of students from different cultures, regardless the self system working in the cultures. To some extent, the finding in the current study is in accordance with the findings in a study by Moeller, Theiler \& Wu (2012) that goal setting, with other variables, can lead to self-regulation and better performance in language learning (p. 154). They state that goal setting is commonly regarded as one of the strategies that encourages 
learner autonomy. As discussed earlier, learner autonomy can be interpreted as a sign that language learners are more self-regulated learners and they will use metacognitive strategies, which proved to be significantly correlated with their language performance in the current study.

The empirical evidence that metacognitive strategies were significantly correlated with language performance is contradictory with the finding in a study by Murray (2010). The data in Murray's study indicates a generally low positive correlation between the use of language learning strategies and classroom achievement. In Murray's study, which involved native speakers of English learning Korean as a foreign language, the data on the use of learning strategies were collected through the Strategy Inventory of Language Learning (SILL). It might be argued that in the study the language learning strategies the participants employed might not be inventoried in the SILL. This argument is indicated in a study by Park (2011), which involved Korean EFL university students. He suggests that the SILL should be reinvestigated so that the data collected by the SILL will not mislead studies of language learning strategies.

The relationship among motivation, metacognitive strategies and language performance indicate that students' motivation predicted their use of language learning strategies, and, in turn, their learning strategies predicted their language performance. Therefore, it may be interpreted that language motivation predicts learning success through the mediation of learning strategies, specifically metacognitive learning strategies.

\section{Conclusion}

This study investigated how students' motivation in the context of EFL was classified under different orientations and how the orientations were correlated with the use of learning strategies and language performance. It is found that in the context of EFL in Indonesia three motivational orientations of language motivation do exist; they are extrinsic motivation, international orientation and intrinsic motivation. This study provides evidence that the language motivation predict language performance through the mediation of the use of metacognitive strategies.

This study is not without limitations. The two questionnaires: the questionnaire for motivational orientations and the questionnaire for metacognitive strategies have been developed in predefined questionnaires, as a result of which, their effectiveness might have been undermined. Therefore, more advanced statistical analyses can be undertaken in order to have more reliable findings. Further research may consider more items to collect data on language motivation, and consider factor analyses and structural equation modelling to analyse the data in order to generate more representative results.

\section{References}

Abrar-Ul-Hassan, S. (2014). A study of the motivational patterns of learners of English for academic and professional purposes. TESOL Journal, 5(1).

Gardner, R.C. \& Lambert, W.E. (1959). Motivational variables in second-language acquisition. Canad. J. Psychol., 13(4).

Gardner, R.C. \& Lambert, W.E. (1972). Attitudes and motivation in second language learning. Massachusetts: Newbury House Publisher.

Gardner, R.C. (1988). The socio-educational model of second-language learning: Assumptions, Findings, and Issues. Language Learning, 38(1), 101-126.

Gardner, R.C, Tremblay, P.F. \& Masgoret, A. (1997). Towards a full model of second language learning: An empirical investigation. The Modern Language Journal, 81(3).

Gardner, R.C. (2000). Correlation, causation, motivation and second language acquisition. Canadian Psychology, 41(1). Gardner, R. C., Masgoret, A.-M., Tennant, J., Mihic, L.(2004). Integrative motivation: changes during a year-long intermediate-level language course. Language Learning, 54(1), 1-34.

Gass, Susan M. and Selinker, Larry. (1994). Second language acquisition: an introductory course. Hillsdale, New: Jersey. Lawrence Erlbaum

Kafipour, R., Noordin, N \& Pezeshkian, F. (2011). Effects of motivation and gender on the choice of language learning strategies by Iranian postgraduate students. Pertanika J. Soc. Sci. \& Hum. 19 (1), 159 - 171.

Khamkhien, A. (2010). Factors affecting language learning strategy reported usage by Thai and Vietnamese EFL learners. Electronic Journal of Foreign Language Teaching, 7(1), 66-85.

Kissau, S.P., Kolano, L. Q. \& Wang, C. (2010). Perceptions of gender differences in high school students' motivation to learn Spanish. Foreign Language Annals, 43(4), 703 - 721. DOI: 10.1111/j.1944-9720.2010.01110.x.

Kormos J. \& Csizer, K. 2014. The interaction of motivation, self-regulatory strategies, and autonomous learning behavior in different learner groups. TESOL Quarterly, 48(2), 275 - 299.

Lamb, M. (2004). Integrative motivation in a globalizing world. System, 32,3 - 19.

Lamb, M and Wedell, M. (2014). Cultural contrasts and commonalities in inspiring language teaching. Language Teaching Research, 1-18.

Maclntyre. P.D. \& Noels, K. A. (1996).Using social-psychological variables to predict the use of language learning strategies. Foreign Language Annals, 29(3), 373 - 386.

Magogwe, J.M. \& Oliver, R. (2007). The relationship between language learning strategies, proficiency, age and selfefficacy beliefs: A study of language learners in Botswana. System, 35(3), 338-352. 
Moeller, A. J., Theiler, J.M. \& Wu, C. (2012). Goal setting and student achievement: a longitudinal study. The Modern Language Journal, 96(2), 153 - 169.

Murray, B. (2010). Students' language learning strategy use and achievement in the Korean as a foreign language. Foreign Language Annals, 43(4), 624 - 634.

Ngo, H., Spooner-Lane, R. \& Mergler, A. (2015): A comparison of motivation to learn English between English major and non-English major students in a Vietnamese university, Innovation in Language Learning and Teaching, DOI: 10.1080/17501229.2015.1094076

Noels, K.A. Pelletier, L.G., Clement, R., \& Vallerand. R.J. (2000). Why are you learning a second language? Motivational orientations and self-determination theory. Language Learning, 53(S1), 33 -64.

O’Malley, M. J., Chamot, A.U., Stewner- Manzanares, G., Kuper, L. \& Russo, R.P. (1985). Learning strategies used by beginning and intermediate ESL students. Language Learning, 35(1), 21-44.

Oxford, R. (1990). Language learning strategies: What every teacher should know. Boston: Heinle \& Heinle Publishers.

Park, G. (2011). The validation process of the SILL: A confirmatory factor analysis. English Language Teaching, 4(4).

Pintrich, P.R. \& De Groot, E. V. (1990). Motivational and self-regulated learning components of classroom academic performance. Journal of Educational Psychology, 82(1), 33-40.

Pintrich, P.R. (1999). The role of motivation in promoting and sustaining self-regulated learning. International Journal of Educational Research, 31, $459-470$.

Politzer, R. L. \& McGroarty, M. (1985). An exploratory study of learning behaviours and their relationship to gains in linguistics and communicative competence. TESOL, 19(1), 103-123.

Rubin, J. (1975). What the "Good language learner" can teach us. TESOL Quarterly, 9, 41-51.

Schunk, D.H. (2005). Self-Regulated Learning: The Educational Legacy of Paul R. Pintrich. Educational Psychologist, 40(2), pp. 85-94, DOI: 10.1207/s15326985ep4002_3.

Setiyadi, A. B. (2014). Skilled-based categories: An alternative measurement for language learning strategies. Journal of Language Teaching and Research, 5(2).

Sherrod, Drury. (1982). Social psychology. New York: Random House.

Sheinker, J. \& Sheinker, A. (1989). Metacognition approach to study strategies. Maryland: Aspen Publishers, Inc.

Stratton, Peter and Hayes, Nicky. (1988). A student's dictionary of psychology. London: Edward Arnold.

Su, M.M. \& Duo, P. (2010). EFL learners' language learning strategy use as a predictor for self-directed learning readiness. The Journal of Asia TEFL, 7(2), 153-176.

Tang, S.W., Ting, S.L. \& Mohd Jaafar, N. (2011). Attitudes and motivation of Malaysian secondary students towards learning English as a second language: A case study. 3L: The Southeast Asian Journal of English Language Studies, 17(1), 40 - 54.

Vallerand, R. J., Pelletier, L. G. \& Koestner, R. (2008). Reflections on Self-Determination Theory. Canadian Psychology, 49(3), 257-262.

Warden, C.A. \& Lin, H.J. (2000). Existence of integrative motivation in an Asian EFL setting. Foreign Language Annals, 33(5), $535-545$.

Vallerand, R. J., Pelletier, L. G. \& Koestner, R. (2008). Reflections on Self-Determination Theory. Canadian Psychology, 49(3), 257-262.

Watson , M., Mcsorley, M., Foxcroft C. \& Watson, A. (2004). Exploring the motivation orientation and learning strategies of first year university learners. Tertiary Education and Management, 10(3), 193-207.

Wenden, A. (1991). Learner strategies for learner autonomy. New York: Prentice Hall.

Zhang, L \& Seepho, S. (2013). Metacognitive strategy use and academic reading achievement: Insights from a Chinese context. Electronic Journal of Foreign Language Teaching, 10(1), 54 - 69. 